\title{
A Study of Noninvasive Cardiac Output and Other Cardiorespiratory Parameters in Various Neurosurgical Positions
}

\author{
${ }^{1}$ Hemangi S Karnik, ${ }^{2}$ Aparna A Nerurkar, ${ }^{3}$ Nishant Bawankule
}

\begin{abstract}
Background: Neurosurgical patients are operated in supine, prone, lateral, and sitting positions, which cause physiological changes in cardiorespiratory parameters. Noninvasive cardiac output (NICO) monitor developed by Novametrix Medical System Inc is a noninvasive cardiac output monitor, which also measures and displays other parameters like stroke volume, cardiac index, pulmonary capillary blood flow, alveolar and dead space ventilation, peak flow rates, airway pressures, and respiratory volumes. We felt that a study using the NICO monitor in anesthetized patients undergoing neurosurgery in different positions would quantify the cardiopulmonary changes, identify risk factors, and improve intraoperative management.
\end{abstract}

Materials and methods: A total of 40 consecutive patients undergoing neurosurgical procedures-20 in prone, 16 in lateral and 4 in sitting position-were studied. The hemodynamic and cardiorespiratory parameters were noted in supine position about 15 minutes after induction of general anesthesia using standard protocol and 15 minutes after giving surgical position using NICO monitor.

Conclusion: We conclude that under anesthesia, the prone and sitting positions negatively affect derived cardiac parameters like cardiac output, cardiac index, and stroke volume, and lateral position tends to improve these parameters while the respiratory parameters are not significantly affected.

Keywords: Lateral position, Neurosurgery, NICO monitor, Noninvasive cardiac output, Positioning under anesthesia, Prone position, Sitting position.

How to cite this article: Karnik HS, Nerurkar AA, Bawankule N. A Study of Noninvasive Cardiac Output and Other Cardiorespiratory Parameters in Various Neurosurgical Positions. Res Inno Anaesth 2016;1(1):19-24.

Source of support: Nil

Conflict of interest: None

\section{INTRODUCTION}

Changes in cardiorespiratory parameters often occur with change of position. These changes have been studied in experimental animals, ${ }^{1}$ healthy volunteers, ${ }^{2,3}$ and

\footnotetext{
${ }^{1}$ Professor, ${ }^{2}$ Additional Professor, ${ }^{3}$ Assistant Professor

${ }^{1-3}$ Department of Anaesthesiology, LTMMC and LTMGH Mumbai, Maharashtra, India
}

Corresponding Author: AparnaANerurkar, Additional Professor Department of Anaesthesiology, D-104, Presidential Towers, LBS Marg, Ghatkopar (West), Mumbai, Maharashtra, India, Phone: +919819101466, e-mail: draparnanerurkar@gmail.com anesthetized patients ${ }^{4}$ using mainly invasive methods to measure cardiac output. With the availability of a noninvasive monitor which measures cardiac and respiratory parameters, we felt that a study assessing the cardiorespiratory changes in different surgical positions would be helpful in defining risk factors and improving intraoperative management.

Neurosurgical procedures including intracranial and spine surgeries require different patient positions like supine, prone, lateral, and sitting for optimum surgical access. We decided to use the NonInvasive Cardiac Output (NICO) monitor developed by Novametrix Medical System Inc (600 Unicorn Park Dr \# 4, Woburn, MA 01801, United States) to measure parameters like cardiac output, stroke volume, cardiac index, pulmonary capillary blood flow, minute ventilation (MV), alveolar minute ventilation (MValv), tidal volume (TV), dead space, peak inspiratory pressure (PIP), and peak expiratory flow (PEF) and document differences with change in position. Any major adverse effect related with positioning were also noted.

\section{MATERIALS AND METHODS}

After Institutional Review Committee approval, the study was carried out in 40 consenting, adult neurosurgical patients, of either sex, between 18 and 60 years of age, of American Society of Anesthesiologists Physical Status Classification I, II, or III, undergoing elective surgeries in prone, lateral, or sitting position. Exclusion criteria were preexisting restrictive, obstructive, or infective respiratory diseases, associated cardiovascular diseases, hemodynamically unstable patients, weight $>90 \mathrm{~kg}$, height $<145 \mathrm{~cm}$, Glasgow Coma Score (GCS) $<11$, and emergency intracranial procedures.

\section{METHODOLOGY}

A complete clinical history and examination including patient height and weight and all relevant investigations were carried out and written consent was obtained.

Patients were taken on table; pulse oximeter, cardioscope, and blood pressure (BP) cuff were attached and all vital parameters were noted. Peripheral and central venous access was obtained and central venous pressure $(\mathrm{CVP})$ was measured. Patients having CVP less than $3 \mathrm{~cm}$ 
of water were excluded. All patients received $10 \mathrm{ml} / \mathrm{kg}$ normal saline in the first 30 minutes.

All patients received intravenous (IV) injection of glycopyrrolate $0.004 \mathrm{mg} / \mathrm{kg}$, Ranitidine $1 \mathrm{mg} / \mathrm{kg}$, Pentazocine $0.5 \mathrm{mg} / \mathrm{kg}$, and Midazolam $0.05 \mathrm{mg} / \mathrm{kg}$ as premedication. Injection thiopental sodium 4-6 mg $/ \mathrm{kg}$ IV and injection vecuronium $0.1 \mathrm{mg} / \mathrm{kg}$ IV were used for induction of general anesthesia and tracheal intubation. Anesthesia was maintained with $\mathrm{O}_{2}+\mathrm{N}_{2} \mathrm{O}(50: 50)+$ propofol + vecuronium bromide infusions. Controlled ventilation using circle absorber system with Datex Ohmeda Excel 210 SE anesthesia machine and ventilator was used. An arterial blood gas sample was collected and sent for analysis.

Approximately 15 minutes after induction, all the baseline vital parameters were noted. With the patient in supine position, the NICO monitor was attached to the breathing system with adjusted rebreathing loop as shown in Figure 1. The patient data in the form of weight in kilogram, height in centimeter, and arterial

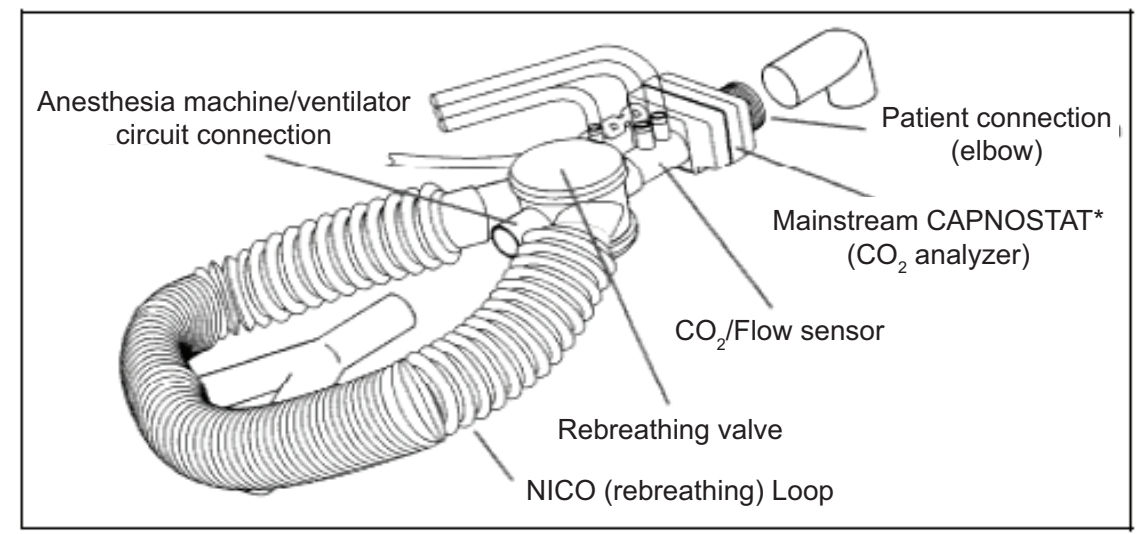

NICO rebreathing loop

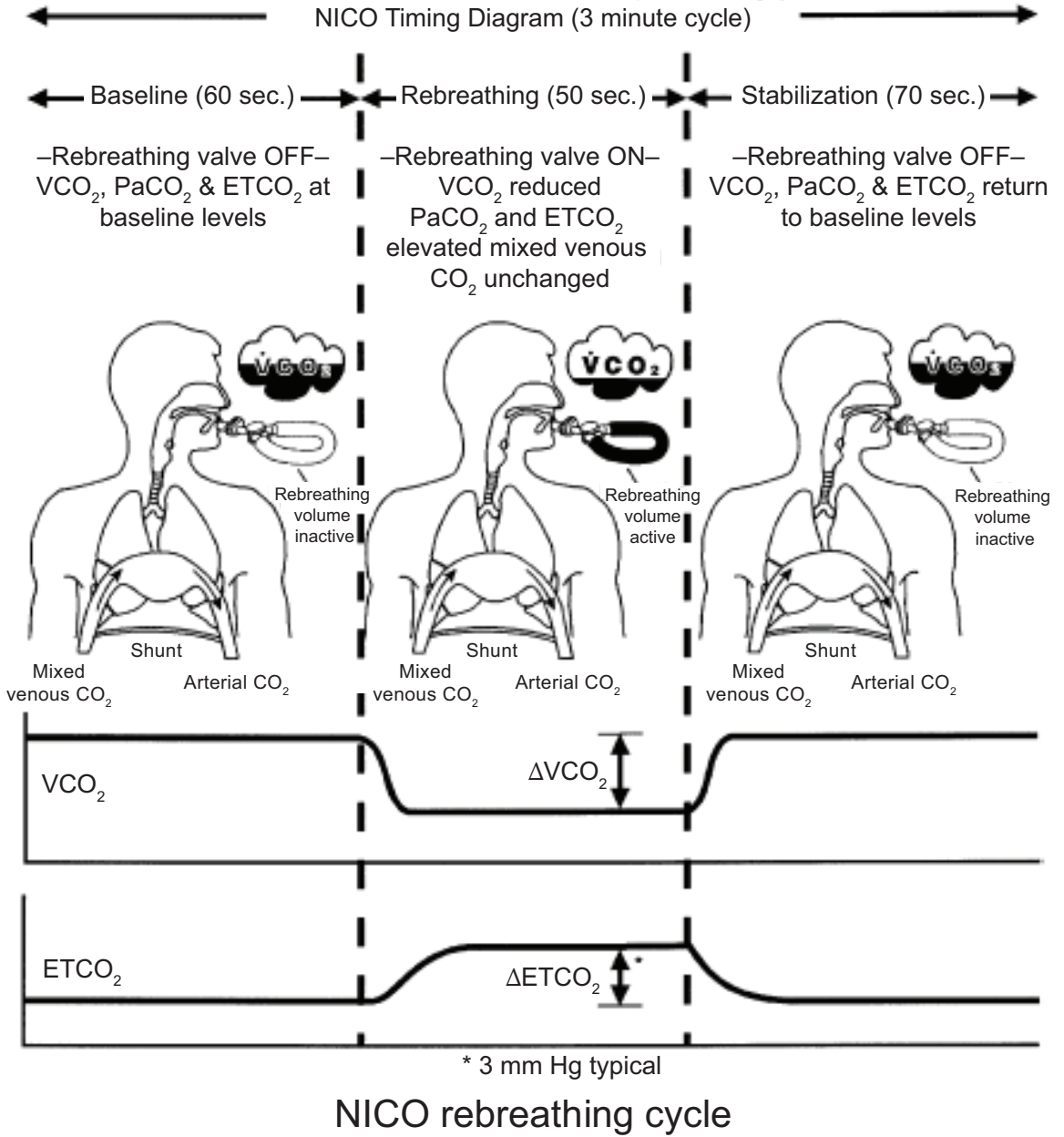

Fig. 1: Noninvasive cardiac output working principle 
Noninvasive Cardiac Output Monitoring in Various Neurosurgical Positions

blood gases were fed into the NICO monitor and NICO pulse oximeter probe was attached. The following cardiorespiratory parameters were noted: HR (heart rate), $\mathrm{BP}, \mathrm{CVP}, \mathrm{SpO}_{2}$ (oxygen saturation), $\mathrm{RR}$ (respiratory rate), MValv, MV, PIP, TV, PEF, the baseline $\mathrm{CO}_{2}$ elimination $\left(\mathrm{VCO}_{2}\right)$, and $\mathrm{ETCO}_{2}$ (end tidal carbon dioxide).

The rebreathing cycle was then started. This consisted of diversion of the patient's inhaled and exhaled gases every 3 minutes through the NICO loop for 50 seconds by the rebreathing valve, preventing normal volumes of $\mathrm{CO}_{2}$ from being eliminated. As a result, $\mathrm{VCO}_{2}$ decreased and the concentration of $\mathrm{CO}_{2}$ in the pulmonary artery $\left(\mathrm{CaCO}_{2}\right)$ increased, which was reflected in the $\mathrm{ETCO}_{2}$. The monitor, utilizing the differential Fick principle for $\mathrm{CO}_{2}$, calculated and displayed the derived parameters like stroke volume, cardiac output, cardiac index, and pulmonary capillary blood flow. Three such consecutive readings were taken and the average of these readings was noted.

The required neurosurgical position-prone, lateral, or sitting-was thereafter given, taking care not to hamper respiration, keeping the abdomen free, and padding all pressure points. Vertical bolsters were used to give prone position. While giving the sitting position, an additional $10 \mathrm{ml} / \mathrm{kg}$ of lactated Ringer's solution was infused and crepe bandages were applied on lower limbs.

A total of 15 minutes after positioning, all the cardiorespiratory parameters mentioned above were noted. Keeping the ventilator settings constant, the rebreathing cycle was initiated, and the average of the three readings for each of the derived parameters was noted. Any major cardiorespiratory complication related to change in position was also noted.

The data thus obtained were subjected to statistical analysis using paired and unpaired student's $t$-test and chi-square test for each position. A p value $<0.05$ was considered as significant and $p$ value $<0.005$ was considered as highly significant.
Table 1: Demography of the patients and surgeries

\begin{tabular}{llll}
\hline Parameters & $\begin{array}{l}\text { Prone } \\
\text { position }\end{array}$ & $\begin{array}{l}\text { Lateral } \\
\text { position }\end{array}$ & $\begin{array}{l}\text { Sitting } \\
\text { position }\end{array}$ \\
\hline No. of patients $(\mathrm{n})$ & 20 & 16 & 04 \\
Mean age (years) & $35.45 \pm$ & $38.06 \pm$ & $30.75 \pm$ \\
& 13.85 & 10.56 & 5.12 \\
Sex (M/F) & $12 / 8$ & $8 / 8$ & $2 / 2$ \\
Mean height $(\mathrm{cm})$ & $161.30 \pm$ & $161.63 \pm$ & $161.50 \pm$ \\
& 6.55 & 8.40 & 5.50 \\
Mean weight $(\mathrm{kg})$ & $57.35 \pm$ & $58.69 \pm$ & $56.00 \pm$ \\
& 8.81 & 8.45 & 6.27 \\
Intracranial surgeries & 04 & 15 & 04 \\
Spine surgeries & 16 & 01 & 00 \\
\hline
\end{tabular}

\section{RESULTS AND ANALYSIS}

Table 1 shows demographic and surgery-wise distribution of patients. Only four patients were given sitting position as it had fallen out of favor at that time.

Table 2 and Graph 2 show the changes in cardiovascular parameters with change of position. The mean HR reduced in prone and lateral position and increased in the sitting position. Though statistically significant, these changes were clinically significant only in sitting position and happened in spite of additional IV fluids given before and during positioning in these patients. Mean systolic BP showed a statistically significant $(\mathrm{p}<0.05)$ but clinically insignificant decrease in patients given prone position and increase in lateral position. All patients in the sitting position showed a marked decrease in mean systolic pressure. However, the small sample size precludes any statistical significance.

The prone position was associated with a statistically very highly significant decrease in the mean cardiac output from $5.48 \pm 1.10$ to $4.19 \pm 0.85 \mathrm{l} / \mathrm{min}(\mathrm{p}=0.000)$ (Table 2 and Graph 1), statistically highly significant decrease in mean stroke volume from $60.90 \pm 16.91$ to $53.05 \pm 15.08 \mathrm{ml}$, and a decrease in cardiac index and pulmonary capillary blood flow.

Table 2: Cardiovascular parameters with change of position

\begin{tabular}{|c|c|c|c|c|c|c|c|c|c|}
\hline \multirow[b]{2}{*}{ Parameters } & \multicolumn{3}{|c|}{ Prone } & \multicolumn{3}{|c|}{ Lateral } & \multicolumn{3}{|c|}{ Sitting } \\
\hline & Before & After & $p$-value & Before & After & $p$-value & Before & After & $p$-value \\
\hline Heart rate $(\mathrm{bpm})$ & $\begin{array}{l}89.65 \pm \\
14.00\end{array}$ & $\begin{array}{l}84.40 \pm \\
12.62\end{array}$ & 0.022 & $\begin{array}{l}87.38 \pm \\
10.75\end{array}$ & $\begin{array}{l}82.69 \pm \\
12.22^{*}\end{array}$ & 0.021 & $\begin{array}{l}78.00 \pm \\
11.77\end{array}$ & $\begin{array}{l}86.00 \pm \\
9.09^{*}\end{array}$ & 0.022 \\
\hline Systolic blood pressure $(\mathrm{mm} \mathrm{Hg})$ & $\begin{array}{l}117.80 \pm \\
6.38\end{array}$ & $\begin{array}{l}114.70 \pm \\
5.32\end{array}$ & 0.024 & $\begin{array}{l}115.38 \pm \\
6.22\end{array}$ & $\begin{array}{l}120.00 \pm \\
7.04\end{array}$ & 0.037 & $\begin{array}{l}121.50 \pm \\
8.69\end{array}$ & $\begin{array}{l}103.50 \pm \\
4.72\end{array}$ & 0.007 \\
\hline Cardiac output (I/min) & $\begin{array}{l}5.48 \pm \\
1.10\end{array}$ & $\begin{array}{l}4.19 \pm \\
0.85\end{array}$ & 0.000 & $\begin{array}{l}4.08 \pm \\
0.63\end{array}$ & $\begin{array}{l}4.38 \pm \\
0.76\end{array}$ & 0.067 & $\begin{array}{l}4.75 \pm \\
0.71\end{array}$ & $\begin{array}{l}4.30 \pm \\
0.57\end{array}$ & 0.037 \\
\hline Stroke volume (ml) & $\begin{array}{l}60.90 \pm \\
16.91\end{array}$ & $\begin{array}{l}53.05 \pm \\
15.08\end{array}$ & 0.001 & $\begin{array}{l}64.81 \pm \\
13.12\end{array}$ & $\begin{array}{l}69.50 \pm \\
14.54\end{array}$ & 0.011 & $\begin{array}{l}74.50 \pm \\
10.63\end{array}$ & $\begin{array}{l}66.50 \pm \\
8.22\end{array}$ & 0.022 \\
\hline Cardiac index $\left(\mathrm{l} / \mathrm{min} / \mathrm{m}^{2}\right)$ & $\begin{array}{l}3.32 \pm \\
0.85\end{array}$ & $\begin{array}{l}2.87 \pm \\
0.87\end{array}$ & 0.000 & $\begin{array}{l}2.82 \pm \\
0.38\end{array}$ & $\begin{array}{l}3.00 \pm \\
0.63\end{array}$ & 0.111 & $\begin{array}{l}3.05 \pm \\
0.30\end{array}$ & $\begin{array}{l}2.80 \pm \\
0.28\end{array}$ & 0.015 \\
\hline $\mathrm{PCBF}(\mathrm{I} / \mathrm{min})$ & $\begin{array}{l}4.82 \pm \\
0.90\end{array}$ & $\begin{array}{l}4.22 \pm \\
0.99\end{array}$ & 0.000 & $\begin{array}{l}2.94 \pm \\
0.46\end{array}$ & $\begin{array}{l}3.01 \pm \\
0.70\end{array}$ & 0.509 & $\begin{array}{l}3.47 \pm \\
0.15\end{array}$ & $\begin{array}{l}3.20 \pm \\
0.00\end{array}$ & 0.035 \\
\hline
\end{tabular}

PCBF: Pulmonary capillary blood flow 

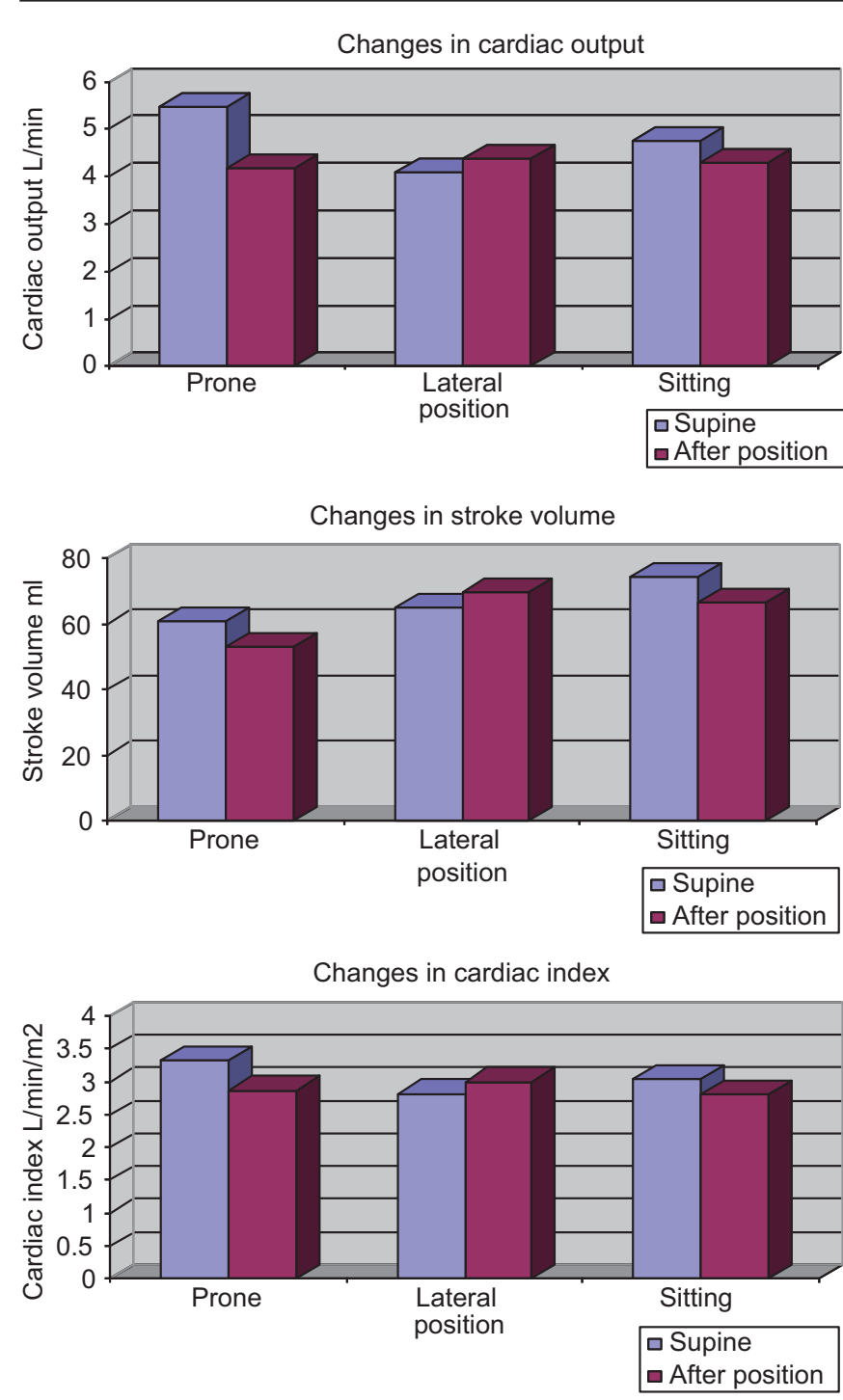

Graph 1: Graphs of cardiac output, stroke volume, and cardiac index
The lateral position showed statistically insignificant increase in cardiac output from $4.08 \pm 0.63$ to $4.38 \pm 0.76$ $1 / \mathrm{min}$, statistically significant increased stroke volume from $64.81 \pm 13.12$ to $69.50 \pm 14.54 \mathrm{ml}$, and a small increase in cardiac index and pulmonary capillary blood flow.

The sitting position showed statistically significant decreased cardiac output from $4.75 \pm 0.71$ to $4.30 \pm 0.57$ $1 / \mathrm{min}$, decreased stroke volume from $74.50 \pm 10.63$ to $66.50 \pm 8.22 \mathrm{ml}$, decreased mean cardiac index from 3.05 \pm 0.30 to $2.80 \pm 0.281 / \mathrm{min} / \mathrm{m}^{2}$, and decreased pulmonary capillary blood flow.

Table 3 summarizes the respiratory changes with positioning. There was no change in expired TV, dead space, alveolar TV, PIP, PEF, or change in $\mathrm{ETCO}_{2}$ following any position. Significant reduction in MV from $5.54 \pm$ 0.68 to $5.40 \pm 0.68 \mathrm{l} / \mathrm{min}$ with corresponding reduction in MValv $(\mathrm{p}<0.05)$ was noted in the prone position. No significant change in MV was noted in lateral position. All patients who were given sitting position showed a significant increase in both MV and MValv. Carbon dioxide elimination reduced significantly from $121.05 \pm$ 30.77 to $112.30 \pm 26.49 \mathrm{ml} / \mathrm{min}(\mathrm{p}=0.025)$ after prone positioning, but no significant change from baseline was noted in lateral or sitting position.

There were no position-related adverse effects noted during the study.

\section{DISCUSSION}

A change in patient position causes cardiorespiratory effects due to change in venous return, peripheral pooling of blood, altered resistance to diaphragmatic move-

Table 3: Respiratory parameters with change of position

\begin{tabular}{|c|c|c|c|c|c|c|c|c|c|}
\hline \multirow[b]{2}{*}{ Parameters } & \multicolumn{3}{|c|}{ Prone } & \multicolumn{3}{|c|}{ Lateral } & \multicolumn{3}{|c|}{ Sitting } \\
\hline & Before & After & $p$-value & Before & After & $p$-value & Before & After & $p$-value \\
\hline $\mathrm{MV}(\mathrm{I} / \mathrm{min})$ & $\begin{array}{l}5.54 \pm \\
0.68\end{array}$ & $\begin{array}{l}5.40 \pm \\
0.68\end{array}$ & 0.025 & $\begin{array}{l}4.94 \pm \\
0.38\end{array}$ & $\begin{array}{l}4.95 \pm \\
0.39\end{array}$ & 0.915 & $\begin{array}{l}5.55 \pm \\
0.50\end{array}$ & $\begin{array}{l}3.65 \pm \\
0.20\end{array}$ & 0.014 \\
\hline MValv (I/min) & $\begin{array}{l}3.95 \pm \\
0.64\end{array}$ & $\begin{array}{l}3.80 \pm \\
0.67\end{array}$ & 0.036 & $\begin{array}{l}3.36 \pm \\
0.31\end{array}$ & $\begin{array}{l}3.18 \pm \\
0.30\end{array}$ & 0.002 & $\begin{array}{l}5.85 \pm \\
0.41\end{array}$ & $\begin{array}{l}4.02 \pm \\
0.28\end{array}$ & 0.022 \\
\hline Vte (ml) & $\begin{array}{l}430.98 \pm \\
51.21\end{array}$ & $\begin{array}{l}444.00 \pm \\
4665\end{array}$ & 0.612 & $\begin{array}{l}410.31 \pm \\
48.44\end{array}$ & $\begin{array}{l}413.56 \pm \\
46.36\end{array}$ & 0.130 & $\begin{array}{l}419.00 \pm \\
35 .\end{array}$ & $\begin{array}{l}422.50 \pm \\
36\end{array}$ & 0.310 \\
\hline Vtalv (ml) & $\begin{array}{l}274.05 \pm \\
61.52\end{array}$ & $\begin{array}{l}275.85 \pm \\
64.32\end{array}$ & 0.706 & $\begin{array}{l}248.94 \pm \\
21.86\end{array}$ & $\begin{array}{l}247.25 \pm \\
24.34\end{array}$ & 0.557 & $\begin{array}{l}272.00 \pm \\
20.33\end{array}$ & $\begin{array}{l}277.00 \pm \\
21.81\end{array}$ & 0.195 \\
\hline Vdaw (ml) & $\begin{array}{l}171.25 \pm \\
32.77\end{array}$ & $\begin{array}{l}171.10 \pm \\
32.40\end{array}$ & 0.942 & $\begin{array}{l}146.44 \pm \\
19.40\end{array}$ & $\begin{array}{l}147.31 \pm \\
19.15\end{array}$ & 0.807 & $\begin{array}{l}134.50 \pm \\
4.4\end{array}$ & $\begin{array}{l}138.00 \pm \\
5.16\end{array}$ & 0.432 \\
\hline $\mathrm{PIP}\left(\mathrm{cm} \mathrm{H} \mathrm{H}_{2} \mathrm{O}\right)$ & $\begin{array}{l}14.10 \pm \\
2.15\end{array}$ & $\begin{array}{l}15.45 \pm \\
2.83\end{array}$ & 0.070 & $\begin{array}{l}15.00 \pm \\
2.21\end{array}$ & $\begin{array}{l}14.94 \pm \\
2.14\end{array}$ & 0.849 & $\begin{array}{l}15.50 \pm \\
0.57\end{array}$ & $\begin{array}{l}15.75 \pm \\
1.25\end{array}$ & 0.638 \\
\hline PEF (I/min) & $\begin{array}{l}37.30 \pm \\
5.93\end{array}$ & $\begin{array}{l}38.15 \pm \\
6.05\end{array}$ & 0.073 & $\begin{array}{l}34.63 \pm \\
2.24\end{array}$ & $\begin{array}{l}35.06 \pm \\
2.29\end{array}$ & 0.263 & $\begin{array}{l}33.75 \pm \\
1.25\end{array}$ & $\begin{array}{l}34.00 \pm \\
1.63\end{array}$ & 0.718 \\
\hline $\mathrm{VCO}_{2}(\mathrm{ml} / \mathrm{min})$ & $\begin{array}{l}121.05 \pm \\
30.27\end{array}$ & $\begin{array}{l}112.30 \pm \\
26.49\end{array}$ & 0.032 & $\begin{array}{l}155.31 \pm \\
15.05\end{array}$ & $\begin{array}{l}151.38 \pm \\
13.75\end{array}$ & 0.373 & $\begin{array}{l}146.00 \pm \\
5.58\end{array}$ & $\begin{array}{l}143.50 \pm \\
14.27\end{array}$ & 0.744 \\
\hline $\mathrm{ETCO}_{2}(\mathrm{~mm} \mathrm{Hg})$ & $\begin{array}{l}32.60 \pm \\
2.08\end{array}$ & $\begin{array}{l}32.60 \pm \\
2.54\end{array}$ & 1.000 & $\begin{array}{l}33.44 \pm \\
1.63\end{array}$ & $\begin{array}{l}32.56 \pm \\
1.03\end{array}$ & 0.115 & $\begin{array}{l}32.50 \pm \\
1.0\end{array}$ & $\begin{array}{l}33.25 \pm \\
0.95\end{array}$ & 0.486 \\
\hline
\end{tabular}

MV: Minute ventilation; MValv: Alveolar minute ventilation; PIP: Peak inspiratory pressure; PEF: Peak expiratory flow; $\mathrm{VCO}_{2}: \mathrm{CO}_{2}$ elimination; $\mathrm{ETCO}_{2}$ : End tidal carbon dioxide 
ment, and ventilation perfusion mismatch along with the blunting of autonomic nervous system under general anesthesia. Heart rate and BP can be monitored clinically or by regularly used monitors. But parameters like stroke volume, cardiac output, cardiac index, alveolar ventilation, and airway pressure need special or invasive monitors like arterial cannulation, pulmonary artery catheterization, airway pressure monitors, etc. Anoninvasive monitor measuring most of these parameters would definitely add to the armamentarium of the anesthesiologist.

Non invasive cardiac output is a multichannel, multifunctional monitor useful in patients with endotracheal tube in situ under general anesthesia. The noninvasive measurement of cardiac output is done using the partial rebreathing technique and application of collected data to the differential Fick equation. The monitor uses a rebreathing loop with valve to create partial rebreathing and collects data on the changes in the rate of $\mathrm{VCO}_{2}$ and $\mathrm{ETCO}_{2}$. It subsequently applies this data to the differential Fick equation to calculate cardiac output.

The differential Fick equation for partial rebreathing cardiac output can be reduced by derivation as follows: ${ }^{5}$

$$
\mathrm{CO}=\frac{\mathrm{VCO}_{2 \mathrm{~N}}-\mathrm{VCO}_{2 \mathrm{R}}}{\mathrm{CaCO}_{2 \mathrm{~N}}-\mathrm{CaCO}_{2 \mathrm{R}}}=\frac{\Delta \mathrm{VCO}_{2}}{\Delta \mathrm{CaCO}_{2}}=\frac{\Delta \mathrm{VCO}_{2}}{\Delta \mathrm{ETCO}_{2}}
$$

where $\mathrm{CO}$ represents the cardiac output, $\mathrm{VCO}_{2 \mathrm{~N}}$ and $\mathrm{VCO}_{2 \mathrm{R}}$ are the volumetric $\mathrm{CO}_{2}$ elimination, $\mathrm{CaCO}_{2 \mathrm{~N}}$ and $\mathrm{CaCO}_{2 \mathrm{R}}$ are the arterial $\mathrm{CO}_{2}$ concentrations during normal and rebreathing periods, respectively, and $\triangle \mathrm{VCO}_{2}$ and $\triangle \mathrm{CaCO}_{2}$ represent the changes in $\mathrm{VCO}_{2}$ and $\mathrm{CaCO}_{2}$ between normal and rebreathing periods. Since the change in $\mathrm{CaCO}_{2}$ is reflected in and measured by the change in $\mathrm{ETCO}_{2}$, cardiac output is equal to the ratio of change in rate of volumetric $\mathrm{CO}_{2}$ elimination and change in $\mathrm{ETCO}_{2}$ levels.

Haryadi et $\mathrm{al}^{6,7}$ and Bailey et $\mathrm{al}^{8}$ evaluated this technique and found it to be an easy-to-use, automated, clinically acceptable continual measurement of cardiac output. The small increase in $\mathrm{ETCO}_{2}$ was not found to be harmful and could be easily tolerated by the patient. Loeb et $\mathrm{al}^{9}$ while comparing NICO monitor with invasive bolus and continuous thermodilution technique and Kothari et $\mathrm{al}^{10}$ while comparing it with bolus thermodilution technique, thermal-based continuous cardiac output, pulse contour cardiac output technique concluded that NICO is least expensive and easy to use. Similarly, Botero et $\mathrm{al}^{11}$ found it to be a good alternative to pulmonary artery catheterization (PAC) and direct arterial flow techniques for cardiac output measurement.

\section{Cardiovascular Parameters}

A fall in cardiac output in prone position is expected due to reduced venous return caused by increased intra-abdominal pressure with compression of inferior vena cava and abdominal aorta and decreased thoracic and ventricular compliance. However, the magnitude of reduction in the present study was more than expected, given the fact that HR and systolic BP remained relatively stable. Blood pressure was probably maintained due to peripheral vasoconstriction with increased systemic vascular resistance as well as pulmonary vascular resistance as documented in a study by Backofen and Schauble. ${ }^{4}$

Wadsworth et $\mathrm{al}^{2}$ had found similar results in a study of 20 healthy volunteers to assess the effect of four different surgical positions. Backofen and Schauble ${ }^{4}$ also noted reduced cardiac output with no change in HR and systolic BP in anesthetized patients during prone positioning. Sudheer et $\mathrm{al}^{12}$ also had similar results.

Srivastava et $\mathrm{al}^{13}$ recommended that the abdomen should be kept free and legs should be elevated in prone position to minimize reduced cardiac output. Alexianu et al ${ }^{14}$ reported a case of hemodynamic collapse in a child positioned prone on transverse bolsters, for spine surgery, treated by repositioning on longitudinal bolsters.

The positive cardiovascular effects in the lateral position may be due to reduction in pressure on inferior vena cava and maintained negative intrathoracic pressure leading to improved venous return and positive inotropic effect. Nakao et $\mathrm{al}^{1}$ in a study in experimental animals concluded that lateral position significantly increases intracardiac pressures and cardiac output. However, Kamenik ${ }^{3}$ found drastic decrease in cardiac index and stroke volume and significant increase in HR in healthy volunteers placed in lateral position with $30^{\circ}$ head up tilt. The head up tilt may explain the discrepancy.

The reduction of all cardiovascular parameters in the sitting position may be attributed to the peripheral pooling of blood and decreased venous return. Buhre et $\mathrm{al}^{15}$ who measured simultaneous changes in intrathoracic blood volume using thermo dye dilution technique, in anesthetized patients with change of body position, found a significant decrease in intrathoracic blood volume, cardiac index, stroke volume index and arterial pressure.

\section{Respiratory Parameters}

In our study, we found that respiratory parameters were not clinically affected by change in patient positioning. Palmon et $a{ }^{16}$ in their study of effect of type of frame and body habitus on pulmonary mechanics demonstrated that prone positioning during anesthesia results in a frame-dependent decrease in pulmonary compliance with no effect of body mass index. Soro et $\mathrm{al}^{17}$ demonstrated no significant changes in the alveolar dead space to TV ratio but improved oxygenation in prone position. Similarly, Pelosi et $\mathrm{al}^{18}$ found statistically significant 
modifications in respiratory and chest wall resistance, marked improvement in lung volume and oxygenation, and similar delivered TVs in prone position.

Thus, our study demonstrated that prone position and sitting positions showed negative hemodynamic and cardiovascular effects, while the lateral position showed improvement in the cardiovascular parameters as compared with supine position. The respiratory parameters get minimally affected in these positions if the patient is given proper surgical positioning.

\section{CONCLUSION}

We conclude that the prone and sitting positions negatively affect derived cardiac parameters like cardiac output, cardiac index, and stroke volume, while the lateral position tends to improve these parameters. Special care with extra vigilance toward hemodynamic monitoring and fluid management is required during prone and sitting positions. The respiratory parameters do not change significantly. A study involving larger number of patients would be appropriate for finding the effect of sitting position on cardiorespiratory parameters. We also found the NICO monitor to be useful and easy to use. Its use can be recommended in patients undergoing general anesthesia with endotracheal intubation in whom cardiac output needs to be monitored and PAC is difficult, not indicated, or not available.

\section{REFERENCES}

1. Nakao S, Come PC, Miller MJ, Momomura S, Sahagian P, Ransil BJ, Grossman W. Effects of supine and lateral positions on cardiac output and intracardiac pressures: an experimental study. Circulation 1986 Mar;73(3):579-585.

2. Wadsworth R, Anderton JM, Vohra A. The effect of four different surgical prone positions on cardiovascular parameters in healthy volunteers. Anesthesia 1996 Sep;51(9):819-822.

3. Kamenik M. The influence of left lateral position on cardiac output changes after Head-up Tilt measured by impendence cardiography. J Clin Monit Comput 1999 Dec;15(7-8): 519-523.

4. Backofen JE, Schauble JF. Hemodynamic changes with prone positioning during general anesthesia. Anesth Analg 1985;64:194.

5. Jaffe MB. Partial $\mathrm{CO}_{2}$ rebreathing cardiac output-operating principles of the NICO system. J Clin Monit Comput 1999 Aug;15(6):387-401.
6. Haryadi DG, Orr JA, Kuck K, McJames S, Westenskow DR. Partial $\mathrm{CO}_{2}$ rebreathing indirect Fick technique for noninvasive measurement of cardiac output. J Clin Monit Comput 2000;16(5-6):361-374.

7. Haryadi DG, Orr JA, Kuck K, McJames S, Westenskow DR. Evaluation of a partial carbon dioxide rebreathing Fick technique for measurement of cardiac output. Anesthesiology 1998;89(3):A534.

8. Bailey PL, Haryadi DG, Orr JA, Westenskow DR. Partial carbon dioxide rebreathing Fick technique for non-invasive measurement of cardiac output. Anesth Analg 1998 Apr;86(4S): SCA53.

9. Loeb RG, Brown EA, DiNardo JA, Orr JA, Watt RC. Clinical accuracy of a new non-invasive cardiac output monitor. Anesthesiology 1999;91(3A):A474

10. Kothari N, Amaria T, Hegde A, Mandke A, Mandke NV. Measurement of cardiac output: comparison of four different methods. Indian J Thorac Cardiovasc Surg 2003;19: 163-168.

11. Botero M, Hess P, Kirby D, Briesacher K, et al. Measurement of cardiac output during coronary artery bypass grafting (CABG): comparison of pulmonary artery catheter, noninvasive partial $\mathrm{CO}_{2}$ rebreathing, and direct aortic flow. Anesth Analg 2000 Apr;V90(4S):SCA87.

12. Sudheer PS, Logan SW, Ateleanu B, Hall JE. Haemodynamic effects of the prone position: a comparison of propofol total intravenous and inhalational anesthesia. Anesthesia 2006 Feb;61(2):138-141.

13. Srivastava S, Pandey CK. Anesthesia in prone lithotomy position. Can J Anesthesia 2001 Sep;48(8):827.

14. Alexianu D, Skolnick E, Pinto C, Ohkawa S, Roye DP Jr, Solowiejczyk DE, Hyman JE, Sun LS. Severe hypotension in the prone position in a child with neurofibromatosis, scoliosis and pectus excavatum presented for posterior spinal fusion. Anesth Analg 2004 Feb;98(2):334-335.

15. BuhreW,WeylandA,BuhreK, KazmaierS,MurschK,SchmidtM, Sydow M, Sonntag H. Effect of the sitting position on the distribution of blood volume in patients undergoing neurosurgical procedures. Br J Anaesth 2000 Mar;84(3):354-357.

16. Palmon SC, Kirsch JR, Deeper JA, Toung TJK. The effect of prone position on pulmonary mechanics is frame-dependent. Anesth Analg 1998 Nov;87(5):1175-1180.

17. Soro M, Gareia-Perez ML, Belda FJ, Ferrandis R, Aguilar G, Tusman G, Gramuntell F. Effects of prone position on alveolar dead space and gas exchange during general anesthesia in surgery of long duration. Eur J Anesthesiol 2007 May;24(5):431-437.

18. Pelosi P, Croci M, Calappi E, Cerisara M, Mulazzi D, Vicardi P, Gattinoni L. The prone positioning during general anesthesia minimally affects respiratory mechanics while improving functional residual capacity and increasing oxygen tension. Anesth Analg 1995 May;80(5):955-960. 